\title{
Drivers Contributing to the Implementation of Generalized Audit Software (GAS) within Audit Firms in Malaysia
}

\author{
Nor Nadia Normahazan \\ Faculty of Accountancy, Universiti Teknologi MARA, Puncak Alam, Selangor, Malaysia \\ Tel: 60-139-388-868Ｅ-mail: nadianormahazan@gmail.com
}

\begin{abstract}
Intan Salwani Mohamed (Corresponding Author)
Accounting Research Institute, Universiti Teknologi MARA, Shah Alam, Selangor, Malaysia

Tel: 60-355-444-991_E-mail: intan838@uitm.edu.my
\end{abstract}

\begin{abstract}
Nabilah Rozzani
Faculty of Business Management and Professional Studies

Management \& Science University, Shah Alam, Selangor, Malaysia

Tel: 60-129-803-088Ｅ-mail: nabilah.rozzani@gmail.com
\end{abstract}

Received: April 17, 2020 Accepted: June 3, 2020 Published: June 4, 2020

doi:10.5296/ber.v10i2.16862ＵRL: https://doi.org/10.5296/ber.v10i2.16862

\begin{abstract}
Many businesses are moving towards the usage of information technology to be in line with their daily operations. Traditional audit methods are no longer relevant these days. Generalized Audit Software (GAS) is a type of software that is suitable for auditors to perform audit tasks. GAS can assist auditors to improve the effectiveness and efficiency of audit. To date, the development of GAS in audit firms is still low, although many practitioners had argued that auditors can receive greater benefits by using GAS. This research is motivated by an interest in understanding drivers contributing to the implementation of GAS within audit firms located in the central region of Malaysia. Prior studies had placed more focus on internal auditors in large accounting firms, or auditors in other countries. However, there were not many researches being conducted on small and
\end{abstract}


medium-sized audit firms in Malaysia. This study is therefore intended to fill in this gap. Data were collected using questionnaire survey on small and medium-sized audit firms registered with the Malaysian Institute of Accountants (MIA) in the central region of Malaysia. A total of 96 responses were analysed using multiple regression analysis. It was found that performance expectation, effort expectation and facilitating conditions had significantly influenced the implementation of GAS among small and medium-sized audit firms. However, social influence was found to have no significant relationship. The outcome of this study might help audit firms, software developers and academia to increase the usage of GAS to perform audit tasks. Future research should further explore on the influence of gender, age, voluntariness, experience, and other drivers contributing to the implementation of GAS within audit firms.

Keywords: Auditor, Auditor effectiveness, Small and medium-sized audit firm, Audit software, Generalized Audit Software

\section{Introduction}

Since last few decades, the success of a business can be measured at an advanced level with quantification of the business in using information technology (IT), as well as how well the business can fully utilise the IT that they have acquired (Lipaj \& Davidaviciene, 2013). Most private corporations and public organisations choose to invest in IT due to the benefits that they can receive as they start implementing IT within their operation process (Laudon \& Laudon, 2016). One of the impacts of technology development can be seen in the audit industry. Since the 1980s, audit firms have started to use IT as the technology can improve the effectiveness and efficiency of audit tasks (Fischer, 1996). In past studies, researchers had found that auditors need to use technology within their audit process as it helps auditors to increase their effectiveness and efficiency in making decisions related to their audit tasks (DeAngelo, 1981; Sikka, 2009; Sirois \& Simunic, 2010; Janvrin, Bierstaker \& Lowe, 2009).

Private corporations as well as public organisations have to re-engineer their business model by moving their scope of businesses in parallel with advancement of technology, which includes e-business, enterprise resource planning (ERP) system, and other advanced computerised accounting information systems (AIS) (Abu Musa, 2004; Romney \& Steinbart, 2015; Shaikh, 2005). Hence, businesses are now becoming more dependent on computerised information systems. According to Flowerday et al. (2006), a shift towards technology causes a business to store its entire database, especially the ones with accounting data, in full electronic form. An auditor is responsible to provide an opinion to stakeholders with regards to accounting records. To ensure that all accounting records are being prepared in true and fair view, auditors would require assistance using software to check and validate these financial records. The evolution of Electronic Data Interchange (EDI) and Electronic File Transfer (EFT) had caused the traditional audit trail to gradually disappear. Traditional system could no longer support auditors' function to check and validate the accuracy of financial records as many data has been stored electronically in recent years. In response to this phenomenon, auditors will have to change the way they perform their work (Bierstaker et al., 2001; Helms and Mancino, 1998). Auditors also need to check the reliability of systems 
that process and store all these transactions. This additional requirement hence increases the challenges of auditor's work as most audit processes are affected by the electronic storage of accounting data. In the past, data or documents were analysed on paper. However, as businesses start to change their business model, data and documents became automatically stored in digital format. Hence, there is a need for auditors to acquire suitable software to help in processing those data and documents.

Braun and Davis (2003) defined computer-assisted auditing tools and techniques (CAATs) as "technology used by auditors to assist in the completion of an audit work". The usage of CAATs simply means that auditors would use specific software to perform audit work and achieve their objective of auditing (Sayana, 2003). CAATs are one of the developed technologies in the audit industry that are designed to assist both internal and external auditors to perform audit tests and tasks for audit jobs (Braun \& Davis, 2003; Saygili, 2010). Internal auditors, as well as external auditors, may use CAATs to perform audit work, which includes the processing of data that is related to audit significance contained in an entity's information systems (Singleton and Flesher, 2003). There are various CAATs available in the market, which have been widely used by auditors to assist them in performing audit work on digital accounting data. CAATs do not only increase the efficiency and effectiveness of audit profession, but they can also help auditors to improve their work performance, accuracy, quality, efficiency, as well as ensuring timely completion of work and an improvement to the auditor's effectiveness (Curtis \& Payne, 2008; Jacob, 2011).

With CAATs, auditors can improve their work performance as they can perform manual intensive tasks quickly. For example, auditors are able to conduct tests on internal control as described in Public Company Accounting Oversight Board (PCAOB), increase the effectiveness of control as described under Section 404 of the Sarbanes-Oxley Act, and better detect fraud as required by SAS No. 99 (AICPA 2001; AICPA 2006; Banker, Hsihui, \& Yi-Ching, 2002; Curtis \& Payne, 2008; Singleton, 2011). CAATs can be divided into five types, including data testing, integrated test facilities (ITF), parallel simulation, embedded audit modules and generalized audit software (Braun and Davis, 2003). The specific type of CAAT which is widely used by auditors around the globe is Generalized Audit Software (GAS) (Singleton, 2006; Debreceny et al., 2005; Braun and Davis, 2003). GAS is a software that is used by auditors to test systems for accuracy, reliability and risk assessment (Ahmi, 2012; Widuri, 2014). As technology becomes more sophisticated, this software allows external auditors to become more focused on their work, while at the same time increase comprehensive testing and improve audit quality (Isabelle \& Hywel, 2015).

There are many GAS available in market, including Audit Command Language (ACL), Interactive Data Extraction and Analysis (IDEA), TopCAATs, ActiveData for Excel, Panaudit Plus, CA's Easytrieve, Statistical Analysis System (SAS), also Statistical Package for Social Sciences (SPSS) (Debreceny et al., 2005; Singleton, 2006). Usually, larger audit firms would develop their personalised GAS (Bierstaker et al., 2001). GAS offers many functions for auditors to perform their work. These functions include to scan, examine, classifying, summarise, differentiate, sample, apply calculations, translate, and perform other operations of data extraction and data analytics as part of auditing client data (Ahmi \& Kent, 2013). 
The primary objective of this study is to examine the drivers contributing to the implementation of Generalized Audit Software (GAS) within small and medium-sized audit firms located in the central region of Malaysia, with Unified Theory of Acceptance and Use of Technology (UTAUT) as its underlying theory. Further, the specific research objectives of this study are to examine the relationship between Performance Expectancy and implementation of GAS; to examine the relationship between Effort Expectancy and implementation of GAS; to examine the relationship between Social Influence and implementation of GAS; as well as to examine the relationship between Facilitating Conditions and implementation of GAS.

\section{Literature Review}

\subsection{Generalized Audit Software (GAS)}

Most authors refer GAS as CAATTs or CAATs since its earlier applications in the mid-1960s. GAS is a group of CAATTs that assist auditors to perform audit work, where GAS allows auditors to access computerised accounting systems. Auditors may perform audit work using this software, including data extraction, querying, manipulating, summarization and analytical tasks (Boritz, 2003; Ahmi, 2012). According to ISACA (2009), GAS can read various types of databases and formats of computer data. GAS can help auditors to complete their audit task faster as GAS allows auditors to perform various types of queries. Besides that, GAS can also be used to complete mathematical computation and grouping; statistical analysis; sequence checking; duplicate checking; as well as recalculating data with the error.

There are many types of GAS that are available in the market. GAS can be divided into two types, namely commercial GAS, and GAS which is built internally by specific companies. GAS that are commercially available in the market include Audit Command Language (ACL), Interactive Data Extraction and Analysis (IDEA), TopCAATs, ActiveData for Excel, Panaudit Plus, CA's Easytrieve, Statistical Analysis System (SAS), as well as Statistical Package for Social Sciences (SPSS) (Gay and Simnett, 2007).

In the past, many researchers had conducted their studies on various GAS usages. Usages of GAS may vary from basic to advanced applications. For example, GAS can be used in the audit task for data extraction, querying, and sampling (Debreceny et al. 2005; Janvrin, Bierstaker \& Lowe 2008). Auditors may also use GAS in advance or for specific uses such as data mining (Janvrin, Bierstaker \& Lowe 2008), continuous monitoring or auditing (Ahmi \& Kent 2013; Janvrin, Bierstaker \& Lowe 2008) and digital analysis (Cleary \& Thibodeau 2005; Janvrin, Bierstaker \& Lowe 2008).

Besides, auditors may examine the quality of data and quality of the system process; as well as to examine the existence of entities and undertake the analytical review. The auditor may inspect the quality of data by a thorough check of the existence, accuracy, completeness, consistency, and timeliness of data stored on a business' computer (Audit Software, 2012).

\subsection{Implementation of Generalized Audit Software (GAS)}

GAS usages by audit firms are still low and not widespread. Although some audit firms do 
implement GAS, its usage is only limited to several necessary audit applications, such as analytical procedures, report writing, electronic working papers, internet search tools and sampling. They do not extend GAS usage to more advanced features. Auditors in Big Four firms use GAS more with more advanced features as compared to non-Big Four auditors. The nature of clients engaged with Big Four firms contributes majorly to the implementation of GAS. Most clients of the Big Four firms come from more extensive business that has more complex IT systems (Janvrin, Bierstaker \& Lowe, 2008d).

According to Wehner and Jessup (2005), GAS implementation is still low because the acceptance of this software is at a minimal level. An auditor who has prior knowledge from college or attends continuing education courses on audit software is more interested to use GAS compared to auditors who don't have such knowledge. Based on the study by Ahmi (2012), GAS is commonly used by audit firms to audit financial statements. Besides that, GAS is also used to investigate audit work, continuous audit work, and monitoring. GAS is used to audit financial work and used in other types of audits.

\subsection{Unified Theory of Acceptance and Use of Technology (UTAUT)}

Unified Theory of Acceptance and Use of Technology (UTAUT) is formulated based on the theory of the Technology Acceptance Model by Venkatesh. UTAUT includes several theories including Theory of Reasoned Action (TRA), Theory of Planned Behaviour (TPB), Technology Acceptance Model (TAM), Model of PC Utilization (MPCU), Motivational Model (MM), Hybrid Model, Innovation Diffusion Theory (IDT) and Social Cognitive Theory (SCT).

UTAUT explains on factors or intentions of people to use information systems (Venkatesh et al., 2003). UTAUT contains four core factors that contribute to the usage of information systems, which are performance expectancy, effort expectancy, social influence, and facilitating conditions. There are four moderators of critical relationships, which include gender, age, voluntariness, and experience.

According to Venkatesh et al. (2003), performance expectancy is a belief that users can increase their task performance by implementing the system. Effort expectancy means that by using GAS, users believe that they can make work easier to accomplish. Social influence comes when users believe that they have support from other parties to use the system. Facilitating conditions is when users believe that there is organisational and technical infrastructure support for the system that they are considering.

\subsection{Theoretical Framework}

This study adapts four main points from UTAUT as drivers that contribute to the implementation of GAS by small and medium-sized audit firms. Four main points including performance expectancy, effort expectancy, and social influence and facilitating conditions serve as the independent variables. The implementation of GAS remains as a dependent variable to be tested for this study. The theoretical framework was designed and developed as illustrated in Figure 1. 


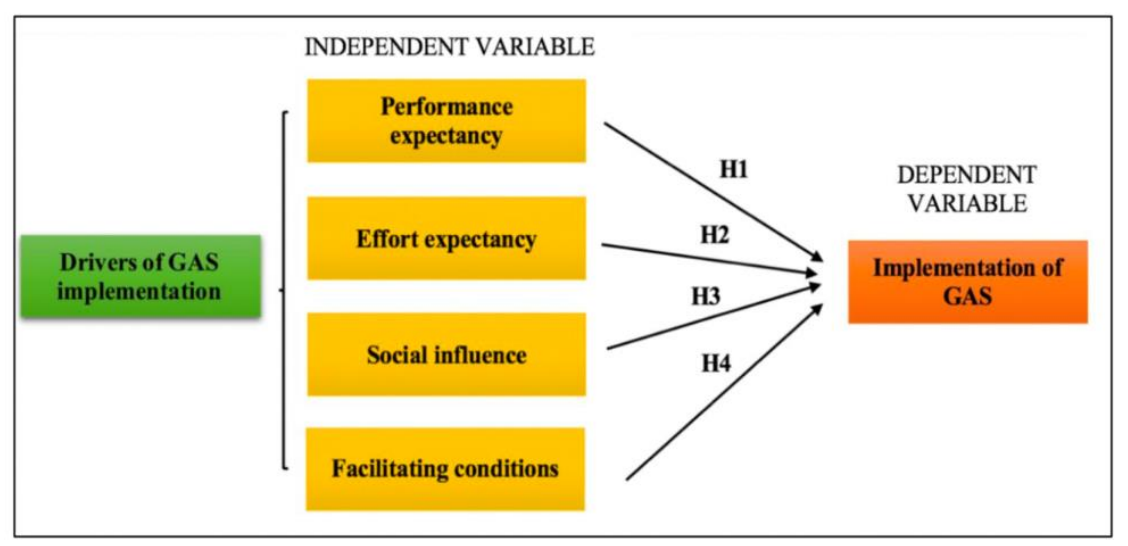

Figure 1. Theoretical Framework

\section{Methodology}

\subsection{Sampling Procedures}

The target population in this study is based on small and medium-sized audit firms that implement GAS and are registered with the Malaysian Institute of Accountants (MIA). These audit firms are in two states of Selangor and Kuala Lumpur. The current number of audit firms registered with MIA is 1464 firms, as obtained from MIA's website. From that number, only 582 audit firms are in the central region of Malaysia. As this study focuses on small and medium-sized audit firms, Big Four firms and audit firms which collaborate with Big Four firms are excluded from this study. From 582, nine audit firms are Big Four firms or firms that collaborate with the Big Four. Six audit firms have been closed and stopped providing audit services. From the remaining 576 audit firms, only 278 audit firms implement GAS and 298 audit firms are still using traditional audit methods. Hence, the total population for small and medium-sized audit firms that are registered with MIA in the central region of Malaysia that implemented GAS is 278 .

The sampling technique used in this study is a simple random sampling technique, which is a probability sampling method. Based on the sample size designed by Sekaran (2003), the population size $(\mathrm{N})$ of 278 goes within the range of 270 to 280 , which would require a sample size (S) from 159 to 162 . The unit of analysis represents an entity that is analysed and used for data collected in this study.

\subsection{Data Collection and Analysis Procedures}

A set of structured questionnaires were distributed for data collection. The questionnaire used in this study are adapted from Ahmi (2012), Chiu and Wang (2008), Davis (1989), Ebrahim (2016), Mahzan and Lymer (2008), Mary and Elizabeth (2014), Nov and Ye (2009), Rogers (1983), Shin (2010), Teo (2009), Terzis and Economides (2011), Udeh (2008), Venkatesh et al. (2003) and Widuri (2014). 278 sets of questionnaires were distributed through electronic mail and Google forms. 96 were successfully returned while 182 were uncollectable due to no response. Hence, 96 usable sample size representing a response rate of 35 percent. 


\section{Macrothink}

Business and Economic Research ISSN 2162-4860 2020, Vol. 10, No. 2

Data obtained from questionnaires then coded and processed using the Statistical Package for Social Science (SPSS) software. Several statistical analyses have been performed to analyse variables such as normality, reliability, correlation, and regression. The multiple regression models for this study were developed to test the hypotheses of the study, which are to determine the relationship between performance expectancy, effort expectancy, social influences and facilitating condition and implementation of GAS.

\subsection{Construct Reliability}

In this study, to measure internal consistency, reliability analysis was performed on each construct. Table 1 shows the result that Cronbach's Alpha for all variables were all above the value of 0.7 .

Table 1. Reliability Statistics

\begin{tabular}{|l|l|}
\hline Variable & Cronbach's Alpha \\
\hline Implementation GAS & $\mathbf{0 . 9 5 9}$ \\
\hline Performance Expectancy & $\mathbf{0 . 7 5 6}$ \\
\hline Effort Expectancy & $\mathbf{0 . 7 1 8}$ \\
\hline Social Influence & $\mathbf{0 . 8 6 9}$ \\
\hline Facilitating Condition & $\mathbf{0 . 8 1 6}$ \\
\hline
\end{tabular}

Overall Cronbach's Alpha $(\mathrm{N}=27)=0.922$

\section{Results and Discussion}

Table 2 shows no correlations were found to go beyond 0.9 to indicate high correlation. Hence, the problem of multicollinearity did not exist.

Table 2. Pearson Correlation Coefficient Test

\begin{tabular}{|l|l|l|l|l|l|}
\hline & $\begin{array}{l}\text { Performance } \\
\text { Expectancy }\end{array}$ & $\begin{array}{l}\text { Effort } \\
\text { Expectancy }\end{array}$ & $\begin{array}{l}\text { Social } \\
\text { Influence }\end{array}$ & $\begin{array}{l}\text { Facilitating } \\
\text { Conditions }\end{array}$ & $\begin{array}{l}\text { Implementation } \\
\text { GAS }\end{array}$ \\
\hline $\begin{array}{l}\text { Performance } \\
\text { Expectancy }\end{array}$ & 1.000 & & & & \\
\hline $\begin{array}{l}\text { Effort } \\
\text { Expectancy }\end{array}$ & $0.405^{* *}$ & 1.000 & & & \\
\hline Social Influence & $0.362^{*}$ & $0.429 *$ & 1.000 & & \\
\hline $\begin{array}{l}\text { Facilitating } \\
\text { Conditions }\end{array}$ & $0.329^{* *}$ & $0.408^{*}$ & $0.624^{* *}$ & 1.000 & \\
\hline $\begin{array}{l}\text { Implementation } \\
\text { GAS }\end{array}$ & $0.441^{* *}$ & $0.454^{*}$ & $0.466^{* *}$ & $0.536^{* *}$ & 1.000 \\
\hline
\end{tabular}

** Correlation is significant at the 0.01 level (1-tailed) 


\section{\Institute ${ }_{\text {Mach }}^{\text {Macrothink }}$}

Table 3 shows that behavioural intention is strongly predicted by facilitating conditions $(\beta=$ $0.387)$, followed by performance expectancy $(\beta=0.321)$, effort expectancy $(\beta=0.283)$ and social influences $(\beta=0.102)$. In total, the 40 per cent of variance in implementation of GAS is explained by the four mentioned variables.

Performance expectancy had a significant influence towards the implementation of GAS ( $\mathrm{p}<$ 0.05). The standardised regression weight $(\beta=.321)$ revealed that when performance expectancy is increased by 1 standard deviation, the implementation of GAS will increase by 0.321 standard deviation. This finding is consistent with results from prior studies, auditors tend to use audit software when the software can serve many advantages to them (Hamzat and Manawonku, 2018; Tabassum et al., 2015; Alshehri, 2012; Mariaka, 2010). Hence, H1, which hypothesized that performance expectancy has a significant relationship with the implementation of GAS is accepted.

Effort expectancy and implementation of GAS had significant influence $(\mathrm{p}<0.05)$. The standardised regression weight $(\beta=0.283)$ revealed that when effort expectancy is increased by 1 standard deviation, the implementation of GAS will increase by 0.283 standard deviation. In previous studies of Sukoharsono and Baridwan (2017); Costel and Munteanu (2013) and Park (2003), effort expectancy is one of the factors that influence the implementation of audit software. When users have low effort expectancy, they might have a high intention to implement the software. Users prefer to implement user-friendly technology since they can save their effort and time to learn new software. Hence, H2, which hypothesized that effort expectancy has a significant relationship with the implementation of GAS is accepted.

Social influence and implementation of GAS had no significant influence ( $\mathrm{p}>0.05)$. The standardised regression weight $(\beta=.102)$ revealed that when Social Influence is increased by 1 standard deviation, the Implementation of GAS will increase by 0.102 standard deviation. In empirical studies of Ebrahim (2016); Janvrin, Bierstaker, and Lowe (2008) and Mahzan and Lymer (2008) agreed that social influence does not support GAS implementation. An outsider will not influence an auditor's decision. To ensure the quality of their tasks, they are responsible for making an effective decision on technology usage without influence by others. In conclusion, social influence does not have a significant relationship with the implementation of GAS. Hence, H3, which hypothesized that social influence has a significant relationship with the implementation of GAS is rejected.

Facilitating conditions and implementation of GAS had significant influence $(\mathrm{p}<0.05)$. The standardised regression weight $(\beta=0.387)$ revealed that when facilitating conditions is increased by 1 standard deviation, the implementation of GAS will increase by 0.387 standard deviation. The availability of facilitating conditions can assist users to be more at ease while using audit software by having adequate resources, knowledge, and support necessary to use audit software. Training programs can assist users in increasing their knowledge and skills. Training is an essential element in influencing audit software usage. This result is consistent with Veerankutty, Ramayah, and Ali (2018); Ebrahim (2016) and Pedrosa (2015). Conclusively, facilitating conditions does play a role in influence the 
implementation of GAS. Hence, H4, which hypothesized that facilitating conditions have a significant relationship with the implementation of GAS is accepted.

Table 3. Coefficient for Multiple Regression

\begin{tabular}{|l|l|l|l|l|}
\hline Hypotheses & Model & B $^{1}$ & P value $^{2}$ & Result $^{3}$ \\
\hline $\mathrm{H}_{1}$ & Performance Expectancy-> Implementation GAS & .321 & .017 & Accept \\
\hline $\mathrm{H}_{2}$ & Effort Expectancy-> Implementation GAS & .283 & .048 & Accept \\
\hline $\mathrm{H}_{3}$ & Social Influence-> Implementation GAS & .102 & .385 & Reject \\
\hline $\mathrm{H} 4$ & Facilitating Conditions-> Implementation GAS & .387 & .004 & Accept \\
\hline
\end{tabular}

Notes: ${ }^{1}$ Regression coefficient

${ }^{2}$ Statistical significant of the test

${ }^{3}$ Result on Hypothesis

Referring to Table 4 of the model summary, the value of the multiple correlation coefficient between predictors and outcome was $\mathrm{R}=0.634$. With $\mathrm{R}^{2}$ of 40.2 per cent (squared multiple correlation), it was forecasted that predictors of implementation of GAS had explained 40.2 per cent of its variance. Adjusted $\mathrm{R}^{2}$ indicated how effectively the model was generalized, which showed 37.6 per cent of the overall model.

Table 4. Model Summary: Behavioural Intention as Dependent Variable

\begin{tabular}{|l|l|l|l|l|}
\hline Model & R & R Square & Adjusted R Square & Std. Error of the Estimate \\
\hline 1 & $.634^{\mathrm{a}}$ & .402 & .376 & .39099 \\
\hline
\end{tabular}

a. Predictors: (Constant), Facilitating Conditions, Performance Expectancy, Effort

Expectancy, Social Influence

Since facilitating conditions is the strongest predictor for implementation of GAS, it should be given strong emphases to encourage more auditors to have confidence and positive intentions in utilizing new audit technology, as well as to enhance their job performance. Focus on facilitating conditions can lead to an increase in the number of voluntary implementations of GAS that can immediately impact audit team work's effectiveness and efficiency (Curtis \& Payne, 2014).

\section{Conclusion}

This study examined the drivers contributing to the implementation of Generalized Audit Software (GAS) within audit firms. Results showed that performance expectancy, effort expectancy and facilitating conditions have a significant relationship with the implementation of GAS. Furthermore, the findings could also give a potential implication on audit firms in Malaysia that have not yet implement GAS to change their preference from traditional methods to GAS. This can assist them in creating positive perceptions from outsiders towards 
audit firms. Future research about drivers contributing to the implementation of Generalized Audit Software (GAS) within audit firms should be explored further on the moderators of critical relationships, which include gender, age, voluntariness, experience and other drivers contributing to the implementation of Generalized Audit Software (GAS) within audit firms. Furthermore, as the present study only took audit firm located in the central region of Malaysia as a sample, future studies could lengthen their sample by including all audit firms located in Malaysia to ensure better results to be obtained. A case study research is also suggested as it can give more insightful results compared to survey research.

\section{References}

AbuMusa, A. A. (2004). Auditing E-Business: New Challenges for External Auditor. Journal of American Academy of Business.

Ahmi, A., \& Kent, S. (2013). The utilization of Generalized Audit Software (GAS) by External Auditors. Managerial Auditing Journal, 28(2), 88-113.

https://doi.org/10.1108/02686901311284522

Alshehri, M. A. (2012). Using the UTAUT Model to Determine Factors Affecting Acceptance and Use of E-government Services in the Kingdom of Saudi Arabia.

American Institute of Certified Public Accountants (AICPA). (2001). The Effect of Information Technology on the Auditor's Consideration of Internal Control in a Financial Statement Audit. Statement of Auditing Standards No. 94. New York NY: AICPA.

American Institute of Certified Public Accountants (AICPA). (2006). Audit Risk Exposure Standards. Statements of Auditing Standards New York NY: AICPA.

Audit Software (Computer Assisted Audit Technique). (2012). Best Practices in Questionnaire Design. Hanover Research. [Online] Available:

http://shodhganga.inflibnet.ac.in/bitstream/10603/167813/13/13_chapter\%205.pdf

Banker, R. D., Hsihui, C., \& Yi-Ching, K. (2002). Impact of Information Technology on Public Accounting Firm Productivity. Journal of Information Systems, 16, 209-222.

http://dx.doi.org/10.2308/jis.2002.16.2.209

Bierstaker, J. L., Burnaby, P., \& Thibodeau, J. (2001). The Impact of Information Technology on the Audit Process: An Assessment of the State of the Art and Implications for the Future. Managerial Auditing Journal, 16, 159. https://doi.org/10.1108/02686900110385489

Boritz, J. E. (2003), Computer Control and Audit Guide, 12th ed., University of Waterloo, Waterloo, Ontario.

Braun, R. L., \& Davis, H. E. (2003). Computer-Assisted Audit Tools and Techniques: Analysis and Perspectives. Managerial Auditing Journal, 18, 725.

https://doi.org/10.1108/02686900310500488

Chiu, C. M., \& Wang, E. T. G. (2008). Understanding Web-Based Learning Continuance Intention: The Role of Subjective Task Value. Information \& Management, 45(3), 194-201. 
https://doi.org/10.1016/j.im.2008.02.003

Cleary, R., \& Thibodeau, J. C. (2005). Applying Digital Analysis Using Benford's Law to Detect Fraud: The Dangers of Type I Errors. Auditing: A Journal of Practice \& Theory, 24, 77. https://doi.org/10.2308/aud.2005.24.1.77

Costel, C. M. (2013). Arguments On Using Computer-Assisted Audit Techniques (CAAT) And Business Intelligence To Improve The Work Of The Financial Auditor. Management Strategies Journal, 26(4), 212-220.

Curtis, M. B., \& Payne, E. A. (2008). An Examination of Contextual Factors and Individual Characteristics Affecting Technology Implementation Decisions in Auditing. International Journal of Accounting Information Systems, 9, 104-121.

https://doi.org/10.1016/j.accinf.2007.10.002

Curtis, M. B., \& Payne, E. A. (2014). Modeling Voluntary CAAT Utilization Decisions in Auditing. Managerial Auditing Journal, 29(4), 304-326.

https://doi.org/10.1108/MAJ-07-2013-0903

Davis, F. D. (1989). Perceived Usefulness, Perceived Ease of Use, and User Acceptance of Information Technology. MIS Quarterly, 13(3), 319-339. https://doi.org/10.2307/249008

DeAngelo, L. E. (1981). Auditor Size and Audit Quality. Journal of Accounting and Economics, 3, 183-199. https://doi.org/10.1016/0165-4101(81)90002-1

Debreceny, R., Lee, S., Neo, W., \& Toh, J. S. (2005). Employing Generalized Audit Software in the Financial Services Sector Challenges and Opportunities. Managerial Auditing Journal, 20(6), 605-618. https://doi.org/10.1108/02686900510606092

Ebrahim, M. M. (2016). Factors Affecting the Adoption of Computer Assisted Audit Techniques in Audit Process: Findings from Jordan. Business and Economic Research.

Fischer, M. J. (1996). Realizing the benefits of new technologies as a source of audit evidence: An interpretive field study. Accounting, Organizations and Society, 21, 219-242. https://doi.org/10.1016/0361-3682(95)00005-4

Flowerday, S., Blundell, A., \& Vonsolms, R. (2006). Continuous Auditing Technologies and Models: A Discussion. Computers \& Security, 25(5), 325-331.

https://doi.org/10.1016/j.cose.2006.06.004

Gay, G., \& Simnett, R. (2007). Auditing and Assurance Services in Australia. Sydney, McGraw-Hill.

Hamzat, S., \& Manawonku, I. (2018). Infuence of Performance Expectancy and Facilitating Conditions on use of Digital Library by Engineering Lecturers in universities in South-West, Nigeria.

Helms, G. L., \& Mancino, J. (1998). Wave good-bye to the paper trail. Electronic auditor. [Online] Available: http://www.aicpa.org/pubs/jofa/apr98/helms.htm 
Isabelle, S., \& Hywel, B. (2015). The Future of Assurance How Technology is Transforming The Audit. [Online] Available:

https://www.ey.com/Publication/vwLUAssets/EY-emeia-fso-assurance-viewpoint-technology /\$FILE/EY-emeia-fso-assurance-viewpoint-technology.pdf

ISACA (2009). CISA Review Manual. USA.

Jacob, K. A. (2011). The Effect of Computer Technology on the Effectiveness of Audit Firms In Uganda.

Janvrin, D., Bierstaker, J., \& Lowe, D. J. (2008). An Examination of Audit Information Technology Use and Perceived Importance. Accounting Horizons, 22, 1-21.

https://doi.org/10.2308/acch.2008.22.1.1

Laudon, K. C., \& Laudon, J. P. (2016). Management Information Systems: Managing the Digital Firm. Upper Saddle River, N.J: Prentice Hall.

Lipaj, D., \& Davidaviciene, V. (2013). Influence of Information Systems on Business Performance.

Mahzan, N., \& Lymer, A. (2008). Adoption of Computer Assisted Audit Tools and Techniques (CAATTS) by Internal Auditors: Current issues in the UK. In: BAA Annual Conference. Blackpool, pp. 1-46.

Mariaka, K. H. (2010). Computerized Auditing in Public Sector Enterprises: A Study of Kenya National Audit Office (KENAO).

Mary, C. B., \& Elizabeth, P. A. (2014). Modeling Voluntary CAAT Utilization Decisions in Auditing. Managerial Auditing Journal, 29(4), 304-326.

https://doi.org/10.1108/MAJ-07-2013-0903

Naheb, O. A., Sukoharsono, E. G., \& Baridwan, Z. (2017). The Influence of Critical Factor on the Behavior Intention to Computerized Accounting Systems (CAS) in Cement Manufactures in Libya.

Nov, O., \& Ye, C. (2009). Resistance to Change and the Adoption of Digital Libraries: An Integrative Model. Journal of the American Society for Information Science and Technology, 60(8), 1702-1708. https://doi.org/10.1002/asi.21068

Park, J. (2003). Adoption of Mobile Technologies for Chinese Consumers, pp. 196-207.

Pedrosa, I. M. (2015). Computer-Assisted Audit Tools and Techniques Use: Determinants for Individual Acceptance.

Rogers, E. M. (1983). Diffusion of Innovations (4th ed.): The Free Press, New York, NY.

Romney, M. B., \& Steinbart, P. J. (2015). Accounting Information Systems. Upper Saddle River, NJ: Prentice-Hall.

Sayana, S. A. (2003). Using CAATs to Support IS Audit. Information Systems. 
Saygili, A. T. (2010). Taking Advantage of CAATTs During Testing Phase in Financial Audits: An Empirical Study of a Food Processing Company in Turkey. Global J. Manage. BuRes., 10, 113-119.

Sekaran, U. (2003). Research methods for business. New York, NY: John Wiley \& Sons Ltd.

Sekaran, U., \& Bougie, R. (2013). Research Methods for Business: A Skill-Building Approach. 6th Edition, Wiley, New York.

Shaikh, J. M. (2005). E-commerce Impact: Emerging Technology-Electronic Auditing. Managerial Auditing Journal, 20, 408-421. http://dx.doi.org/10.1108/02686900510592089

Shin, D. H. (2010). MVNO services: policy implications for promoting MVNO diffusion. Telecommunications Policy, 34(10), 616-632. https://doi.org/10.1016/j.telpol.2010.07.001

Sikka, P. (2009). Financial Crisis and the Silence of the Auditors. Accounting, Organizations and Society, 34, 868-873. https://doi.org/10.1016/j.aos.2009.01.004

Singleton, T. (2006). Generalized Audit Software: Effective and Efficient Tool for Today's IT Audits. Information Systems Control Journal, 2(1).

Singleton, T. (2006). IT Audit Basics: Generalized Audit Software: Effective and Efficient Tool for Today's IT Audits. Information Systems Control Journal, 2, 11.

Singleton, T. (2011). How the IT Auditor Can Make Substantive Contributions to a Financial Audit. ISACA Journal, 1, 1-3.

Singleton, T., \& Flesher, D. L. (2003). A 25 years retrospective on the IIA's SAC project. Managerial Auditing Journal, 18(1), 39-53. https://doi.org/10.1108/02686900310454237

Sirois L. P., \& Simunic, D. A. (2010). Auditor Size and Audit Quality Revisited: The Importance of Audit Technology. https://doi.org/10.2139/ssrn.1533127

Tabassum, M., Roknuzzaman, M., \& Islam, M. M. (2015). Usage of Digital Library System at a University in Bangladesh. Annals of Library and Information Studies, 62, 94-103.

Teo, T. (2011). Factors Influencing Teachers' Intention to Use Technology: Model Development and Test. Computers \& Education, 57(4), 1-25.

https://doi.org/10.1016/j.compedu.2011.06.008

Terzis, V., \& Economides, A. A. (2011). The Acceptance and Use of Computer Based Assessment. Computers \& Education, 56(4), 1032-1044.

https://doi.org/10.1016/j.compedu.2010.11.017

Udeh, E. P. (2008). Exploring User Acceptance of Free Wireless Fidelity Public Hot Spots: An Empirical Study. An Interdisciplinary Journal on Humans in ICT Environments, 4(2), 144-168. https://doi.org/10.17011/ht/urn.200810245834

Veerankutty, F., Ramayah, T., \& Ali, N. A. (2018). Information Technology Governance on Audit Technology Performance among Malaysian Public Sector Auditors.

https://doi.org/10.3390/socsci7080124 


\section{Macrothink}

Business and Economic Research ISSN 2162-4860 2020, Vol. 10, No. 2

Venkatesh, V., Morris, M. G., Gordon, B. D., \& Davis, F. D. (2003). User Acceptance of Information Technology: Toward a Unified View. MIS Quarterly, 27, 425-478. https://doi.org/10.2307/30036540

Wehner, D., Mann, H., \& Jessup, C. M. (2005). Factors Affecting Generalized Audit Software Usage. In: AAA Midwest Accounting Meeting. St. Louis Missouri.

Widuri, R. (2014). Adoption and Use of Generalized Audit Software by Indonesian Audit Firms. https://doi.org/10.5176/2251-1997_AF14.15

\section{Copyright Disclaimer}

Copyright for this article is retained by the author(s), with first publication rights granted to the journal.

This is an open-access article distributed under the terms and conditions of the Creative Commons Attribution license (http://creativecommons.org/licenses/by/4.0/). 